\title{
FOXC1 identifies basal-like breast cancer in a hereditary breast cancer cohort
}

\author{
Jeff Johnson ${ }^{1}$, Michael Choi ${ }^{1}$, Farnaz Dadmanesh ${ }^{2}$, Bingchen Han ${ }^{1}$, Ying Qu ${ }^{1}$, \\ Yi Yu-Rice ${ }^{1}$, Xiao Zhang ${ }^{3}$, Sanjay Bagaria5, ${ }^{5}$ Clive Taylor ${ }^{6}$, Armando E. Giuliano ${ }^{1,4}$, \\ Farin Amersi ${ }^{1,4}$, Xiaojiang Cui ${ }^{1,4}$ \\ ${ }^{1}$ Department of Surgery, Cedars-Sinai Medical Center, Los Angeles, CA 90048, USA \\ ${ }^{2}$ Department of Pathology, Cedars-Sinai Medical Center, Los Angeles, CA 90048, USA \\ ${ }^{3}$ Biostatistics and Bioinformatics Research Center, Cedars-Sinai Medical Center, Los Angeles, CA 90048, USA \\ ${ }^{4}$ Samuel Oschin Comprehensive Cancer Institute, Cedars-Sinai Medical Center, Los Angeles, CA 90048, USA \\ ${ }^{5}$ Department of Surgery, Mayo Clinic, Jacksonville, FL 32224, USA \\ ${ }^{6}$ Department of Pathology and Laboratory Medicine, Keck School of Medicine, University of Southern California, Los Angeles, \\ CA 90033, USA \\ Correspondence to: Farin Amersi, email: farin.amersi@cshs.org \\ Xiaojiang Cui, email: xiaojiang.cui@cshs.org \\ Keywords: basal-like breast cancer, immunohistochemistry, BRCA, FOXC1, PARP inhibitor \\ Received: June 04, $2016 \quad$ Accepted: September 21, 2016 \\ Published: September 30, 2016
}

\section{ABSTRACT}

Breast cancers arising in the setting of the hereditary breast cancer genes BRCA1 and BRCA2 are most commonly classified as basal-like breast cancer (BLBC) or luminal breast cancer, respectively. BLBC is an aggressive subtype of breast cancer associated with liver and lung metastases and poorer prognosis than other subtypes and for which chemotherapy is the only systemic therapy. Multiple immunohistochemical markers are used to identify the basal-like subtype, including the absence of estrogen receptor alpha, progesterone receptor, and human epidermal growth factor receptor 2. Forkhead box C1 (FOXC1) has been identified as a specific marker expressed in BLBC in general breast cancer cohorts. We examined an institutional cohort of breast cancer patients with germline BRCA1 $(n=46)$ and BRCA2 $(n=35)$ mutations and found that FOXC1 expression on immunohistochemical staining is associated with BRCA1 vs BRCA2 mutations [30/46 vs. 6/35]. In BRCA1 mutant tumors, FOXC1 was expressed in 28/31 BLBC tumors and 2/13 non-BLBC tumors, In BRCA2 mutant tumors, FOXC1 was expressed in 5/5 BLBC tumors and 1/30 non-BLBC tumors. In cell culture models of BRCA1-mutant breast cancer, FOXC1 is associated with increased proliferation and may serve as a marker for sensitivity to PARP-inhibitor therapy with olaparib.

\section{INTRODUCTION}

Gene expression profiling with unsupervised clustering analysis has demonstrated distinct classes within the molecular heterogeneity of breast cancers. Subsequent studies have demonstrated that these molecular classes, which include luminal A, luminal B, Her2 expressing (HER2), and basal-like breast cancer (BLBC), have significant prognostic and predictive value [1-3]. Hereditary breast cancer arising in the setting of germline mutations in BRCA1 and BRCA2 is recognized to generally sort with the BLBC and luminal subtypes of breast cancer, respectively [3, 4]. While these molecular subtypes are defined by clustering analysis of gene expression profiles, in clinical practice these molecular subtypes are approximated by immunohistochemistry (IHC) and fluorescence in situ hybridization (FISH). In this classification system, tumors expressing estrogen receptor $\alpha(\mathrm{ER} \alpha)$ and/or progesterone receptor $(\mathrm{PR})$ with low Ki-67 are categorized as luminal A; ER+ and/or PR+ with high Ki-67 or HER2+ are categorized as luminal B; ER-, PR-, and Her2+ by FISH are categorized as Her2+; and tumors lacking expression of these markers (ER-PR-HER2-) are "triple-negative" and categorized as BLBC [5]. This system has prognostic value and predicts response to specific endocrine or anti-HER2 
therapy [6-10]. BLBC, which lacks ER $\alpha$ and HER2, has no recognized targeted therapy and has a relatively poor prognosis.

Additional IHC markers, such as epidermal growth factor receptor (EGFR) and basal cytokeratins, have been used to improve classification of BLBC, but these may not inform the molecular etiology of the disease and thereby may not serve as predictive markers for future therapy, and to some degree the inclusion of additional markers complicates the classification system and allows for discordant results [11-13]. The forkhead box transcription factor FOXC1 was identified in gene expression studies as a specific biomarker for BLBC. IHC expression of FOXC1 has been shown to be a specific marker for BLBC that has prognostic, even in cases of discrepancy between other IHC markers [12, 14]. Importantly, FOXC1 appears to play a functional role in BLBC, suggesting a potential role as a predictive marker for targeted therapies in development $[14,15]$.

Patients with germline mutations in BRCA1 have a significant risk of developing breast cancer by age 70 , recently estimated at $69 \%$ (95\% CI $56 \%-83 \%)$ [16]. Multiple studies have shown that $80-90 \%$, of BRCA1 tumors are BLBC, as opposed to $10-15 \%$ of all tumors $[2,17,18]$. Conversely, approximately $20 \%$ of BLBC tumors show germline or somatic BRCA1 mutation [2]. This is in contrast to the second most common hereditary breast cancer, BRCA2-related breast cancer, which has a significantly different gene expression profile and is typically lower grade, is more differentiated, appears later in life, and belongs to the luminal/ER-positive subtype [4, 19]. Although both BRCA1 and BRCA2 have major functions tied to DNA repair through the homologous repair pathway, the specificity for BRCA1-related tumors to form $\mathrm{BLBC}$ suggests a role for BRCA1 in the regulation of genes related to that subtype. However, as patients with germline BRCA1 mutations represent a specific subclass of BLBC, it is yet to be established whether FOXC1 is also found within these tumors and whether there is a relationship between BRCA1/2 and FOXC1. In this study, we sought to demonstrate the clinicopathologic significance of FOXC1 expression in BRCA-associated breast cancer.

\section{RESULTS}

\section{Clinicopathologic data and immunohistochemistry}

Database review from two institutions identified 46 tumor samples from patients with germline BRCA1 mutations and 35 tumor samples from patients with germline BRCA2 mutations from 1995 to 2013 with available tissue for immunohistochemistry (IHC) staining. Paraffin-embedded tissue sections underwent IHC using a validated monoclonal FOXC1 antibody [14]. FOXC1 staining was considered positive if greater than $15 \%$ of cells demonstrated nuclear staining for FOXC1 (Figure 1). Available demographic and clinical information is noted in Table 1. FOXC1 association with the BLBC subtype was consistent with prior studies of BLBC demonstrating younger age of onset, higher tumor grade, and increased Ki67\%. Also previously demonstrated, FOXC1-associated tumors had fewer lymph node metastases [20]. However, no significant differences were seen in the rates of distant metastases, distant recurrence, disease-free survival, or overall survival, although a trend was seen towards increased locoregional recurrence in $\mathrm{FOXC1} 1+$ tumors $(\mathrm{p}=0.0512)$ (Supplementary Table $\mathrm{S} 1)$. This may reflect relatively short follow-up times, a benefit of increased surveillance, early detection with lead-time bias, and/ or more aggressive treatment among the BRCA-mutant population at our hospital.

Figure 1 demonstrates the relationship between BRCA mutation status, FOXC1 staining, and molecular subtypes. FOXC1 staining was significantly associated with the basal-like phenotype defined by IHC markers (ER-PR-HER2-/EGFR+/CK5/6+): $92 \%$ (33/36) of FOXC $1+$ tumors were basal, and nearly all basal tumors $(92 \% ; 25 / 28)$, demonstrated FOXC1 staining $(p<0.0001)$. Mutations in BRCA1 and BRCA2 were determined as part of patients' usual care with assays performed by Myriad Genetics (Salt Lake City, UT). Consistent with the associated subtypes, FOXC1 was significantly associated with the presence of BRCA1 germline mutation and absence of BRCA2 mutation $(p<0.0007)$. Interestingly, $67 \%(31 / 46)$ of BRCA1 tumors were BLBC, a percentage lower than that reported in other studies [17]. Of the 46 BRCA1 tumors, 30 expressed FOXC1 and 28 of these were BLBC. Among the 35 BRCA2 tumors, six tumors expressed FOXC1 and five were BLBC. These findings demonstrate that FOXC1 is associated with BRCA1-mutant tumors and identifies the BLBC subtype in patients with germline BRCA1/2 mutations.

\section{Gene expression data}

This association is also seen in mRNA expression data. Using the publicly available gene expression data from Larsen et al. (GSE40115), which includes gene expression profiling of 183 breast tumors, including 33 with BRCA1 germline mutation, 22 with BRCA2 germline mutation, and the remainder sporadic [21], we determined levels of FOXC1 between BLBC and nonBLBC for the BRCA1-mutant (Figure 2A) and BRCA2mutant (Figure 2B) tumors. FOXC1 is markedly higher in BLBC compared to non-BLBC for both sets of tumors $(\mathrm{p}<0.0001)$. 


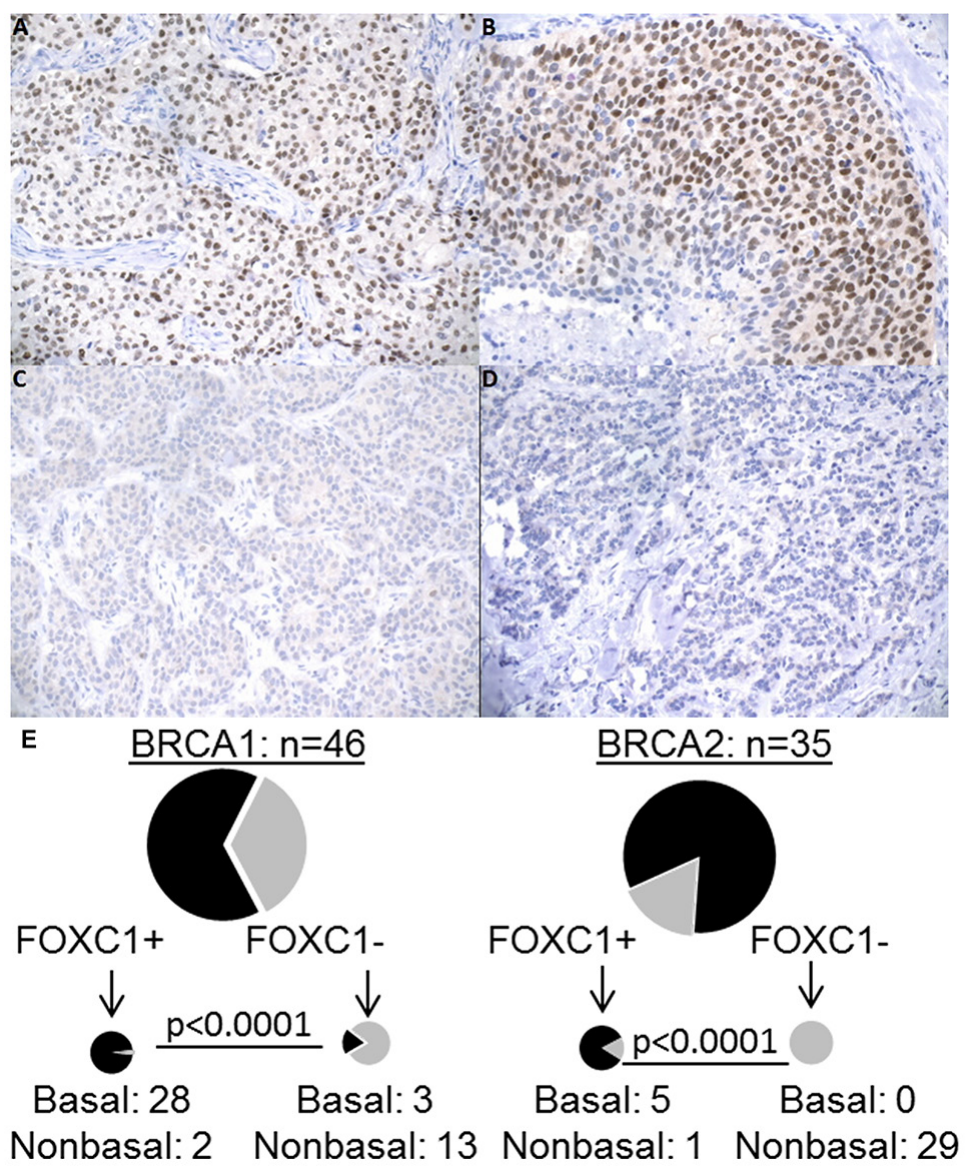

Figure 1: FOXC1 immunohistochemistry, BRCA1/2 mutation status, and molecular subtype. A. BRCA1 mutant, basal molecular subtype with positive nuclear staining. B. BRCA wild-type, basal molecular subtype with strong nuclear positivity. C. BRCA2 mutant, luminal A molecular subtype with negative staining. D. BRCA wild-type, luminal A molecular subtype with negative staining. All images 200X. E. Distribution of BLBC/NonBLBC among FOXC1 IHC positive or negative cells for BRCA1 mutant and BRCA2 mutant tumors. BLCB: Basal-like breast cancer. NonBLBC: Non basal-like breast cancer, including Her2+ and Luminal A and Luminal B tumors.

Table 1: Clinicopathologic data for patients with BRCA mutation status and FOXC1 staining

\begin{tabular}{lccc}
\hline Characteristic & $\begin{array}{c}\text { FOXC1 } \\
\text { n (\%) }\end{array}$ & $\begin{array}{c}\text { FOXC1 } \\
\text { n (\%) }\end{array}$ & P-value \\
\hline No. of patients & 36 & 45 & $0.006^{*}$ \\
$\begin{array}{l}\text { Age at diagnosis } \\
\text { (mean years } \pm \text { SD) }\end{array}$ & $42.9 \pm 13.3$ & $50.7 \pm 11.7$ & $0.286^{* *}$ \\
Tumor Size & & & $<0.0001^{\dagger}$ \\
(mean mm \pm SD) & $21 \pm 9$ & $20 \pm 14$ & \\
Tumor Grade & & & \\
1 & $0(0)$ & $4(100)$ & \\
$\mathbf{2}$ & $3(14)$ & $18(86)$ & $<0.0001^{*}$ \\
$\mathbf{3}$ & $32(58)$ & $23(42)$ & $<0.0001^{*}$ \\
ER Positive & $4(41)$ & $41(91)$ & $<0.0001^{* *}$ \\
PR Positive & $3(7)$ & $38(93)$ & $19.9 \pm 13.6$ \\
Ki67 \% (mean \pm SD) & $50.9 \pm 21.9$ & & \\
\hline
\end{tabular}

*t-test. ** Mann-Whitney U test. $†$ Fisher’s Exact test. + Chi-Square test. 


\section{Cell proliferation and olaparib sensitivity}

To determine whether FOXC1 has functional significance in BRCA1-mutant cells, we performed proliferation assays using control and CRISPR-mediated FOXC1-knockout (FOXC1-KO) SUM149 BRCA1mutant BLBC cells (Figure 3A, Supplementary Figure $\mathrm{S} 1$ ), demonstrating decreased proliferation with FOXC1 knockout (Figure 3B). We also examined sensitivity of BRCA1-mutant cells to olaparib, a PARP inhibitor used in BRCA-mutant cancers to take advantage of synthetic lethality with the homologous repair defect. Control wildtype (WT) SUM149 cells were more sensitive to treatment with $10 \mu \mathrm{M}$ olaparib relative to DMSO vehicle than FOXC1$\mathrm{KO}$ cells (Figure 3C). In examining the four available BRCA1-mutant BLBC cell lines and one BRCA1 wildtype cell line, we found that the BRCA1 mutant cell lines with relatively higher expression of FOXC1 demonstrated sensitivity to $10 \mu \mathrm{M}$ olaparib, whereas HCC1937, a BRCA1-mutant cell line with low FOXC1 expression, did not exhibit sensitivity (Figure 4B). BT549, a BLBC BRCA1 wild-type cell line with high FOXC1 levels (Figure 4A) also did not exhibit sensitivity to olaparib. Combined, these results suggest that FOXC1 is essential for BRCA1-mutant breast cancer cell growth and may predict sensitivity to treatment with olaparib in BRCA1-mutant cells, which warrants further validation using clinical samples.

\section{DISCUSSION}

Prior work has demonstrated a number of genes specifically upregulated in BLBC, although the mechanism of the BLBC phenotype in BRCA1-mutant cancer is yet to be defined. We have demonstrated that FOXC1 can specifically identify BRCA1-mutant BLBC cancer. This and prior data suggests that the BLBC phenotype, and FOXC1 specifically can be regulated by BRCA1 [22]. In addition, the enrichment of FOXC1 and BLBC in BRCA1-mutant tumors may also be explained by development of cancer in FOXC1-expressing luminal progenitor cells, which are enriched in the setting of BRCA1 mutation [23, 24].
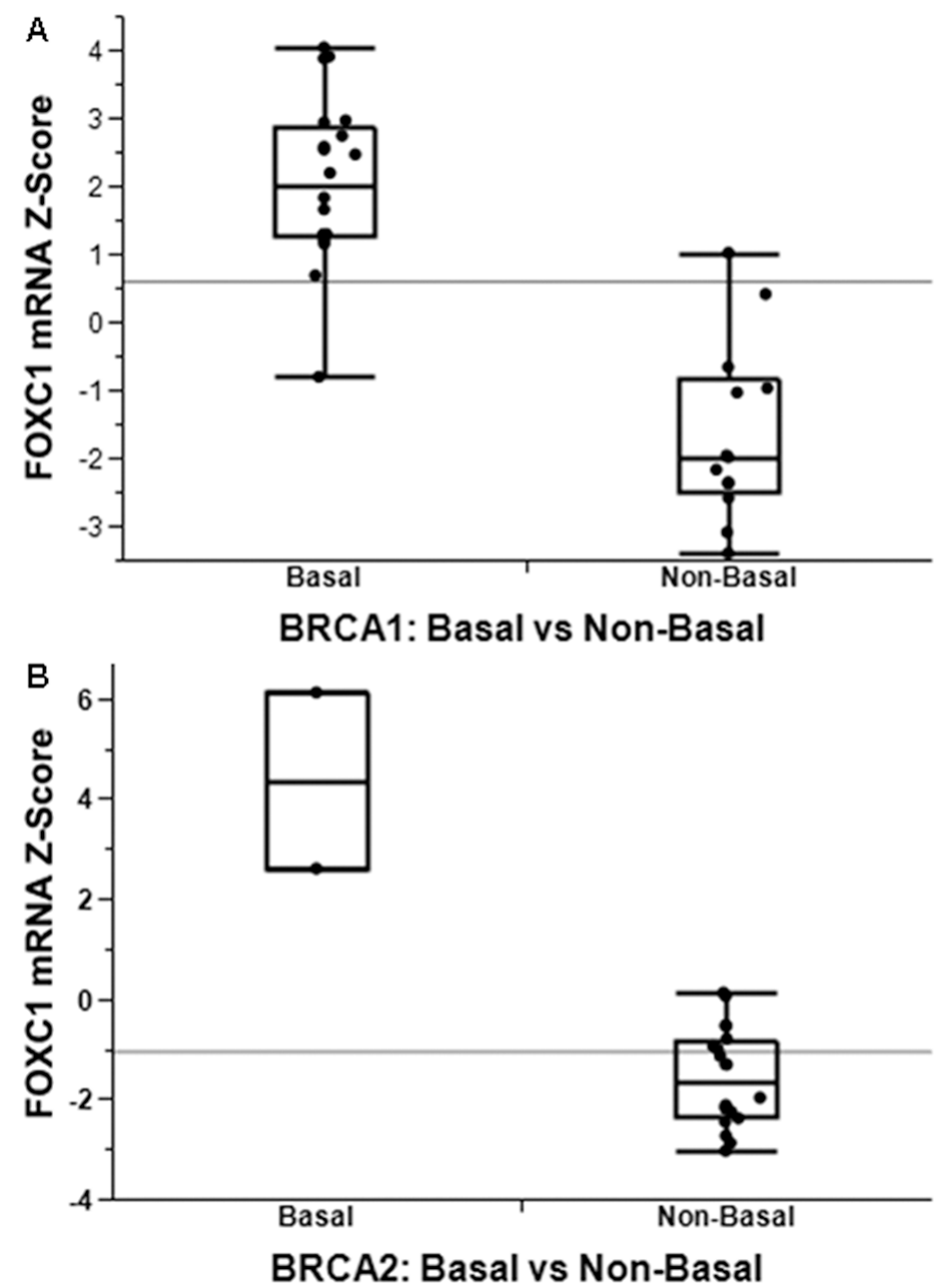

Figure 2: FOXC1 associated with BLBC with functional significance. FOXC1 mRNA is significantly higher in basal-like breast cancer in both patients with both BRCA1 A. and BRCA2 B. mutations. 
FOXC1 is known to play a critical role in embryonic ocular and brain development, with mutations or deletions resulting in glaucoma-related ocular dysgenesis and DandyWalker malformations [25]. Recently, FOXC1 has been demonstrated across a number of tissues to regulate the stem cell niche and stem cell activation/quiescence [2629]. FOXC1 is also expressed in the developing mammary gland, but its exact function has not been described [23, 30]. FOXC1 is also being recognized in a wide range of cancers, including acute myeloid leukemia [31], hepatocellular
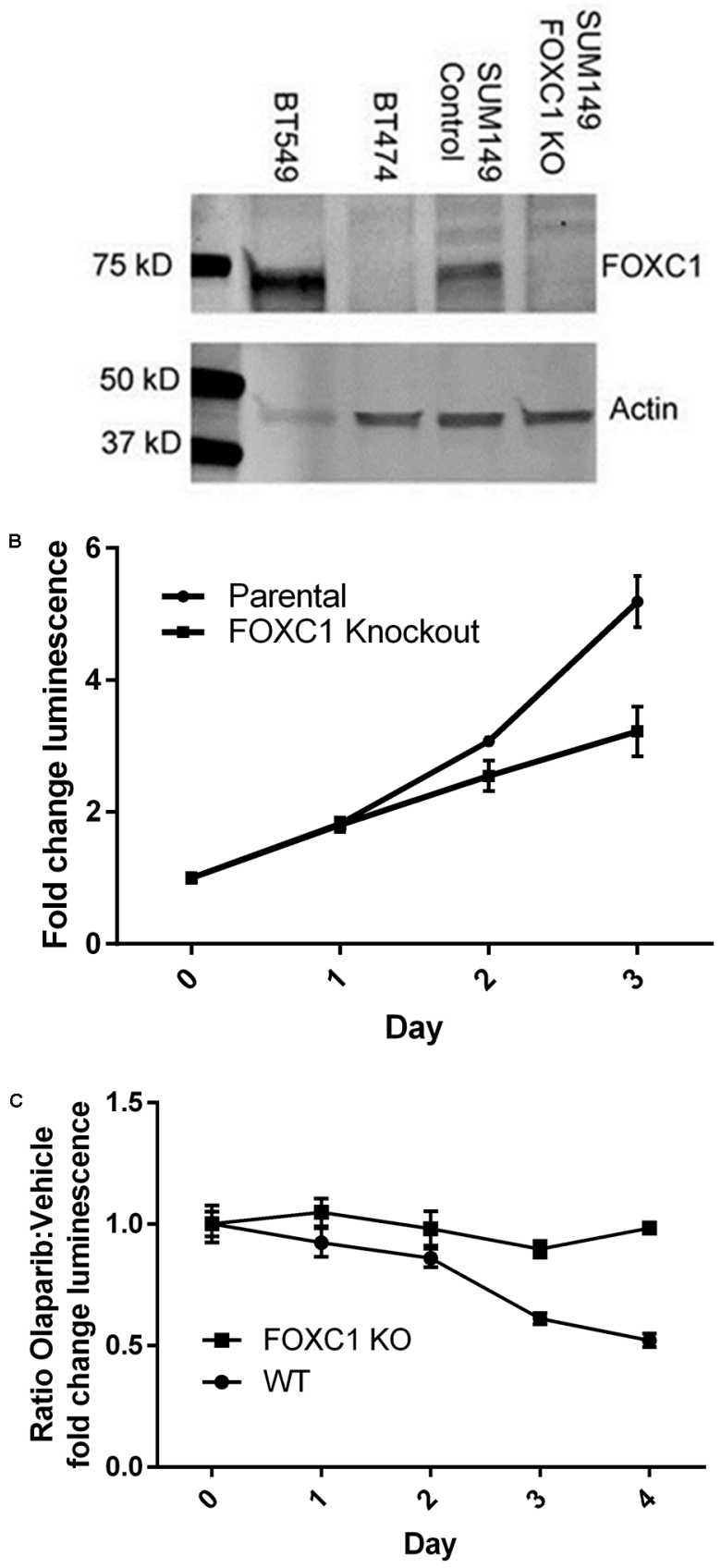

Figure 3: FOXC1 knockdown diminishes proliferation. A. Western blot demonstrating CRISPR knockout of FOXC1 in SUM149. High-FOXC1 BLBC cell line BT549 and low-FOXC1 luminal cell line BT474 used as qualitative controls. B. FOXC1 knockdown results in diminished proliferation compared to FOXC1 wildtype in SUM149 cells. Mean \pm SD for representative experiment with 6 technical replicates. Statistical significance for the difference in fold-change luminescence between parental and knockout cells, $\mathrm{p}<0.01 \mathrm{calculated}$ by Mann-Whitney U test, reached on day 2 of growth. C. SUM149 FOXC1 wild-type cells are more sensitive to olaparib than FOXC1 knockout cells. Ratio of means \pm combined SD for $p<0.01$ calculated by Mann-Whitney U test reached on day 3 of treatment. 
carcinoma [32], renal cell carcinoma [33], gastric cancer [34], and non-small cell lung cancer [35].

In breast cancer, we have demonstrated that $\mathrm{FOXC1}$ plays a role in proliferation in BRCA1-mutant BLBC cells, and prior studies have demonstrated a critical role for FOXC1 in the functional properties of BLBC, driving metastasis, epithelial-mesenchymal transition phenotype, and tumorigenesis [12, 36-39]. Our data shows that BRCA1-mutant SUM149 FOXC1 KO cells continue to proliferate, albeit at a reduced rate, suggesting that other FOXC1-independent pathways may be involved in the proliferation of these cells.

Further, FOXC1 is critical for EGFR-mediated cell proliferation and survival regulated via the ERK and PI3K/Akt pathways [40]. Downstream, FOXC1 have been shown to induce NF- $\mathrm{NB}$ signaling and induction of a SMO-independent Gli2 signaling pathway [15, 39].
Because of the critical role of FOXC1 in BLBC cell function, along with an opposing expression pattern between BRCA1- and BRCA2-mutant breast cancers, it is speculated that BRCA1, not BRCA2, mutationelicited signaling might synergize with FOXC1 action in mammary tumorigenesis. One possible implication of this finding is heterogeneity in the phenotype, and possibly the cells of origin, of germline BRCA-mutation associated tumors. The mammary epithelium is sorted into subgroups representing different stages in the differentiation of tissue from mammary stem cells to one of the mature downstream pathways, basal myoepithelial cells or mature luminal cells [41]. Multiple studies suggest that BRCA1 is essential for the differentiation and maturation of luminal cells, and that BRCA1 mutation may lead to an arrest in differentiation and increase in the number of stem and/ or progenitor cells $[24,41,42]$. This is significant as the
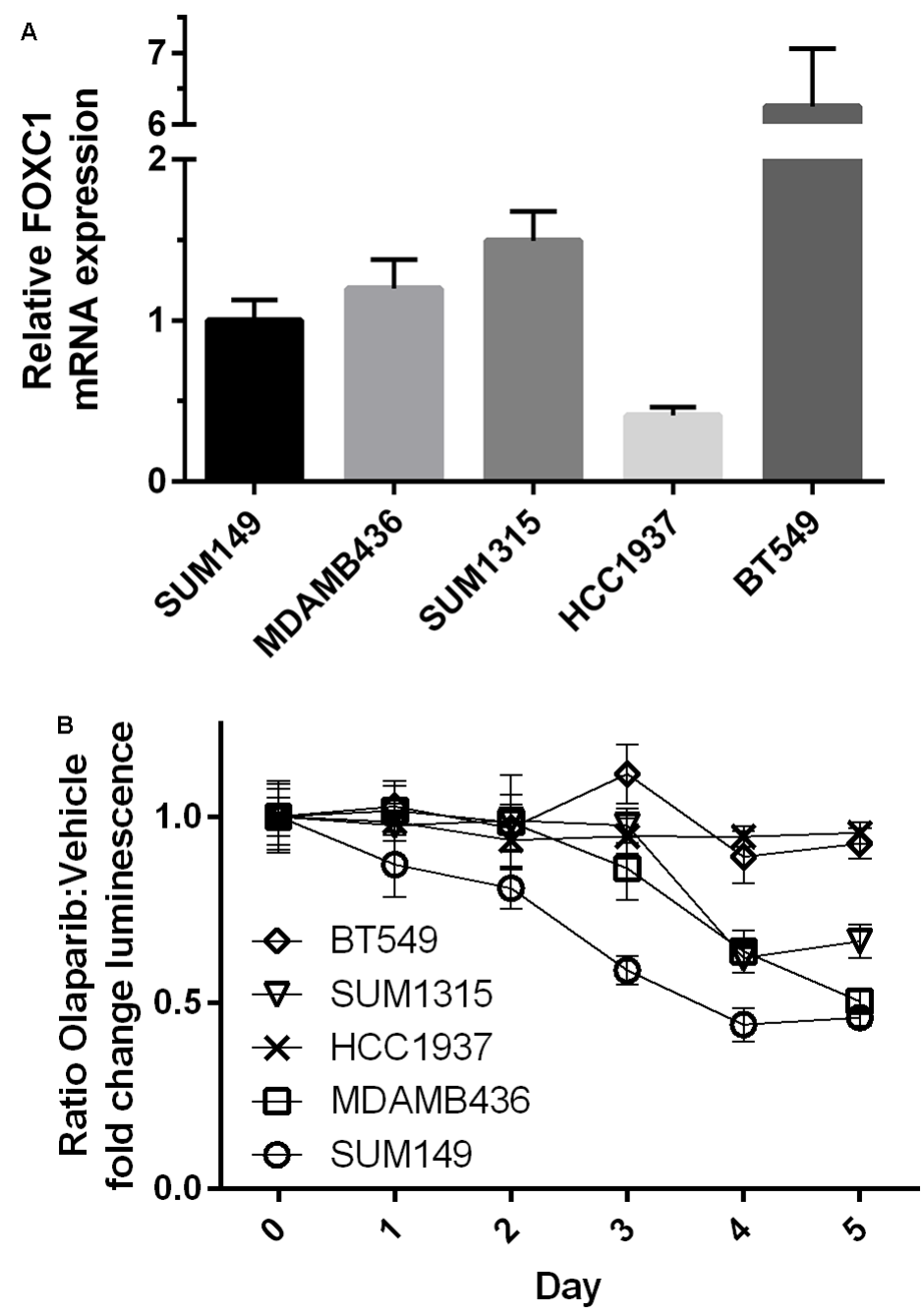

Figure 4: BRCA1-mutant cell line intrinsic FOXC1 level associated with PARPi sensitivity. A. Relative FOXC1 mRNA expression for BRCA1-mutant cell lines and BRCA1 wild-type basal-like cell line BT549. Note Y-axis has been truncated for BT549 expression. BT549 FOXC1 expression significantly greater than all other cell lines $(\mathrm{p}<0.0001)$. HCC1937 FOXC1 expression significantly less than all other cell lines $(\mathrm{p}<0.01)$. B. Sensitivity of BRCA1 mutant cell lines and BT549 to olaparib. Ratio of means \pm combined SD. $\mathrm{p}<0.01$ calculated by Mann-Whitney $\mathrm{U}$ test reached on day 3 of treatment. 
different molecular subtypes have been correlated with different cells of origin along, with BLBC associated with luminal progenitor cells and luminal cancers associated with mature luminal epithelial cells [24, 43]. The presence of FOXC1, which was shown to be induced in luminal progenitor cells, suggests that germline BRCA mutations may cooperate with $\mathrm{FOXC1}$ to induce tumorigenesis in the BLBC subgroup of BRCA-mutant breast cancer. ${ }^{21}$ The heterogeneity demonstrated especially in BRCA1 associated tumors may affect therapeutic options and requires further investigation.

This study also demonstrates that expression of FOXC1 in BRCA1 mutant cell lines correlates with sensitivity to olaparib. Whether this is due to rates of proliferation or another mechanism is yet to be explored, but this, and the specificity of FOXC1 in BRCA1-mutant tumors, suggests a possible role for $\mathrm{FOXC1}$ as a marker for targeted therapy. Certainly the BRCA1-FOXC1 axis deserves further attention as a mechanism for the etiology of BLBC, and ultimately may prove FOXC1 as a marker for targeted therapies against BRCA1 and/or BLBC.

\section{MATERIALS AND METHODS}

\section{Immunohistochemistry}

Data on molecular subtype as well as ER $\alpha, \mathrm{PR}$, Her2, and Ki-67 was collected from pathology reports from surgically resected tumor specimens. IHC of ER $\alpha$, PR, Her2, Ki-67, EGFR, and CK5/6 was performed as part of routine surgical pathology of tumor specimens. IHC staining and interpretation was performed consistent with guidelines published by the American Society of Clinical Oncology/College of American Pathologists [44]. Tissue sections demonstrating any intensity of ER or PR staining (low, moderate, high) in $\geq 1 \%$ of cells were reported as "positive." Ki-67 is reported as a percentage of cells demonstrating nuclear staining, and tumors with $\geq 20 \%$ of cells staining positive are interpreted as "high." [45] Tumors expressing estrogen receptor $\alpha(\mathrm{ER} \alpha)$ and/or progesterone receptor (PR) with low Ki-67 were categorized as luminal $\mathrm{A} ; \mathrm{ER} \alpha+$ and/or $\mathrm{PR}+$ with high $\mathrm{Ki}-67$ or HER2+ were categorized as luminal B; ER $\alpha$ -, PR-, and Her2+ by FISH were categorized as Her2+; and tumors lacking expression of ER $\alpha, \mathrm{PR}$, and HER2 with expression of EGFR and CK5/6 were categorized as BLBC $[5,13,46]$. FOXC1 status was determined by staining of archived formalin-fixed paraffin-embedded breast cancer tissue from surgical specimens using a validated monoclonal FOXC1 antibody (Onconostic Technologies, Inc., Champaign, IL). ${ }^{12}$ Two independent pathologists blinded to BRCA status assessed slides for nuclear staining of FOXC1 and determined the percentage of positive cells. Sections demonstrating positive nuclear staining in $\geq 15 \%$ of cells were deemed positive for FOXC1 staining.

\section{Gene expression arrays}

Data from Larsen et al. (GSE40115) was obtained from the Gene Expression Omnibus [21]. Z-scores for gene expression levels were compared with the MannWhitney U test.

\section{Proliferation assays}

Cells were seeded at $1 \times 10^{3}$ cells/wellin 96 well plates. SUM149 cells were cultured in Ham's F12 nutrient mixture, $5 \%$ fetal bovine serum, and 1\% penicillin/ streptomycin, supplemented $0.01 \mathrm{mg} / \mathrm{ml}$ insulin and $500 \mathrm{ng} / \mathrm{ml}$ hydrocortisone [47]. Luminescence, based on quantity of ATP present, was used a readout for measuring number of viable cells and was determined every 24 hours using CellTiter-Glo Assay (Promega) according to manufacturer protocols. Daily luminescence values were normalized to Day 0 and compared using MannWhitney $U$ test. A single experiment included six technical replicates and all experiments were repeated three times. Data shown are mean \pm SD from a representative experiment.

\section{Drug sensitivity}

Cells were seeded at $1 \times 10^{3}$ cells/well (BT549), $2 \times 10^{3}$ cells/well (SUM1315, HCC1937), $3 \times 10^{3}$ cells/ well (SUM149), or $4 \times 10^{3}$ cell/well (MDA-MB-436) in 96 well plates. Cells were cultured according to previously published protocol [47]. Cells were treated 24 hours after plating with $1 \mu \mathrm{M}$ olaparib in DMSO or equivalent volume of DMSO. Relative cell number was assessed with CellTiter-Glo Assay (Promega) every 24 hours. Daily luminescence values were normalized to Day 0 and are expressed as the ratio of mean values for luminescence for olaparib treated/DMSO treated cells for each cell line on a given treatment day \pm combined SD. A single experiment included six technical replicates and all experiments were repeated three times. Data are from a representative experiment. Daily luminescence values were compared using Mann-Whitney U test.

\section{FOXC1 knockout cells}

The knockout of FOXC1 in SUM149 cells was performed according to the protocol published previously [48]. Briefly, the single guide RNA (sgRNA) for knocking down FOXC1 was designed by an online tool (http://crispr.mit.edu/). The sequence of the sgRNA is 5'-GGGTGCGAGTACACGCTCAT-3'. The sgRNA and its complementary strand were synthesized (ThermoFisher), annealed, and then subcloned into LentiCRISPRv2 vector (Addgene). The cells were infected with LentiCRISPRv2-FOXC1 and then selected with puromycin for 48 hours. The knockout efficiency was evaluated by western blotting. 


\section{qRT-PCR}

Total RNA was extracted and reverse transcription performed using the RNeasy Mini Kit (Qiagen) the QuantiTect Reverse Transcription Kit (Qiagen) according to manufacturer's instructinos. Quantitative PCR was done using an iCycler iQ Real-Time Thermocycler (Bio-Rad Laboratories) [15]. GAPDH was used as an internal control. FOXC1 primers used were: 5'-catccgccacaacctctcget-3' (forward) and 5'-gtgcagcctgtccttctcctcc-3' (reverse). Fold change was calculated with delta delta $\mathrm{Ct}$ value. Bar graphs represent mean \pm SEM of three independent experiments with three technical replicates. Pairwise comparisons analyzed with Tukey's HSD.

\section{Statistics}

Data were analyzed as described using GraphPad Prism version 6 for Windows (GraphPad Software, La Jolla, CA USA) or JMP version 12 for Windows (SAS Institute, Inc., Cary, NC USA). For all statistics, $\mathrm{p}<0.05$ was used for statistical significance. For clinicopathologic variables, normally distributed variables were compared with 2-tailed t-test and non-normally distributed variables with the Mann-Whitney U test. Fisher's Exact test was used for mean comparisons between $>2$ groups. ChiSquare test was used to compare proportions.

\section{CONFLICTS OF INTEREST}

$\mathrm{X}$. Cui is a named inventor on patent applications regarding the role of FOXC1 in cancer. The other authors declare that no conflict of interest exists.

\section{GRANT SUPPORT}

X.C. is supported by National Institutes of Health (CA151610), the Avon Foundation (02-2014-063), Eleanor and Glenn Padnick Discovery Fund in Cellular Therapy, and David Salomon Translational Breast Cancer Research Fund, and the Entertainment Industry Foundation. Giuliano is supported by the Fashion Footwear Charitable Foundation of New York, Inc., Associates for Breast and Prostate Cancer Studies, and the Margie and Robert E. Petersen Foundation. The funders/sponsors had no role in the design and conduct of the study; collection, management, analysis, and interpretation of the data; preparation, review, or approval of the manuscript; and decision to submit the manuscript for publication.

\section{Author contributions}

J.J, F.A., and X.C. conceived and designed the experiments. J.J. performed experiments. M.C., B.H, Y.Q. and Y.Y. assisted with the experiments. F.D. and C.T. performed FOXC1 IHC and analysis. S.B., C.T., F.A., and A.G participated in experimental design, contributed patient data, and participated in manuscript preparation. J.J. and X.C wrote, revised, and edited the manuscript.

\section{REFERENCES}

1. van't Veer LJ, Dai H, van de Vijver MJ, He YD, Hart AA, Mao M, Peterse HL, van der Kooy K, Marton MJ, Witteveen AT, Schreiber GJ, Kerkhoven RM, Roberts C, et al. Gene expression profiling predicts clinical outcome of breast cancer. Nature. 2002; 415:530-536. doi: 10.1038/415530a.

2. Cancer Genome Atlas Network. Comprehensive molecular portraits of human breast tumours. Nature. 2012; 490:61-70. doi: $10.1038 /$ nature 11412 .

3. Perou CM, Sorlie T, Eisen MB, van de Rijn M, Jeffrey SS, Rees CA, Pollack JR, Ross DT, Johnsen H, Akslen LA, Fluge O, Pergamenschikov A, Williams C, et al. Molecular portraits of human breast tumours. Nature. 2000; 406:747752. doi: 10.1038/35021093.

4. Sorlie T, Tibshirani R, Parker J, Hastie T, Marron JS, Nobel A, Deng S, Johnsen H, Pesich R, Geisler S, Demeter J, Perou CM, Lonning PE, et al. Repeated observation of breast tumor subtypes in independent gene expression data sets. Proceedings of the National Academy of Sciences of the United States of America. 2003; 100:8418-8423. doi: 10.1073/pnas.0932692100.

5. Goldhirsch A, Wood WC, Coates AS, Gelber RD, Thurlimann B and Senn HJ. Strategies for subtypes-dealing with the diversity of breast cancer: highlights of the St. Gallen International Expert Consensus on the Primary Therapy of Early Breast Cancer 2011. Annals of oncology. 2011; 22:1736-1747. doi: 10.1093/annonc/mdr304.

6. Barnes DM, Skinner LG and Ribeiro GG. Triple hormonereceptor assay: a more accurate predictive tool for the treatment of advanced breast cancer? British journal of cancer. $1979 ;$ 40:862-865.

7. Tamoxifen for early breast cancer: an overview of the randomised trials. Early Breast Cancer Trialists' Collaborative Group. Lancet. 1998; 351:1451-1467.

8. Spring LM, Gupta A, Reynolds KL, Gadd MA, Ellisen LW, Isakoff SJ, Moy B and Bardia A. Neoadjuvant Endocrine Therapy for Estrogen Receptor-Positive Breast Cancer: A Systematic Review and Meta-analysis. JAMA oncology. 2016. doi: 10.1001/jamaoncol.2016.1897.

9. Stocker A, Hilbers ML, Gauthier C, Grogg J, Kullak-Ublick GA, Seifert B, Varga Z and Trojan A. HER2/CEP17 Ratios and Clinical Outcome in HER2-Positive Early Breast Cancer Undergoing Trastuzumab-Containing Therapy. PloS one. 2016; 11:e0159176. doi: 10.1371/journal.pone.0159176.

10. Pegram MD, Lipton A, Hayes DF, Weber BL, Baselga JM, Tripathy D, Baly D, Baughman SA, Twaddell T, Glaspy JA and Slamon DJ. Phase II study of receptorenhanced chemosensitivity using recombinant humanized 
anti-p185HER2/neu monoclonal antibody plus cisplatin in patients with HER2/neu-overexpressing metastatic breast cancer refractory to chemotherapy treatment. Journal of clinical oncology. 1998; 16:2659-2671.

11. Ray PS, Bagaria SP, Wang J, Shamonki JM, Ye X, Sim MS, Steen S, Qu Y, Cui X and Giuliano AE. Basal-like breast cancer defined by FOXC1 expression offers superior prognostic value: a retrospective immunohistochemical study. Annals of surgical oncology. 2011; 18:3839-3847. doi: 10.1245/s10434-011-1657-8.

12. Ray PS, Wang J, Qu Y, Sim MS, Shamonki J, Bagaria SP, Ye X, Liu B, Elashoff D, Hoon DS, Walter MA, Martens JW, Richardson AL, et al. FOXC1 is a potential prognostic biomarker with functional significance in basallike breast cancer. Cancer research. 2010; 70:3870-3876. doi: 10.1158/0008-5472.CAN-09-4120.

13. Cheang MC, Voduc D, Bajdik C, Leung S, McKinney S, Chia SK, Perou CM and Nielsen TO. Basal-like breast cancer defined by five biomarkers has superior prognostic value than triple-negative phenotype. Clinical cancer research. 2008; 14:1368-1376. doi: 10.1158/1078-0432. CCR-07-1658.

14. Jensen TW, Ray T, Wang J, Li X, Naritoku WY, Han B, Bellafiore F, Bagaria SP, Qu A, Cui X, Taylor CR and Ray PS. Diagnosis of Basal-Like Breast Cancer Using a FOXC1-Based Assay. Journal of the National Cancer Institute. 2015; 107. doi: 10.1093/jnci/djv148.

15. Wang J, Ray PS, Sim MS, Zhou XZ, Lu KP, Lee AV, Lin $\mathrm{X}$, Bagaria SP, Giuliano AE and Cui X. FOXC1 regulates the functions of human basal-like breast cancer cells by activating NF-kappaB signaling. Oncogene. 2012; 31:47984802. doi: 10.1038/onc.2011.635.

16. Rebbeck TR, Mitra N, Wan F, Sinilnikova OM, Healey S, McGuffog L, Mazoyer S, Chenevix-Trench G, Easton DF, Antoniou AC, Nathanson KL, Laitman Y, Kushnir A, et al. Association of type and location of BRCA1 and BRCA2 mutations with risk of breast and ovarian cancer. Jama. 2015; 313:1347-1361. doi: 10.1001/jama.2014.5985.

17. Foulkes WD, Stefansson IM, Chappuis PO, Begin LR, Goffin JR, Wong N, Trudel M and Akslen LA. Germline BRCA1 mutations and a basal epithelial phenotype in breast cancer. Journal of the National Cancer Institute. 2003; 95:1482-1485. doi: 10.1093/jnci/djg050.

18. Prat A, Parker JS, Karginova O, Fan C, Livasy C, Herschkowitz JI, He X and Perou CM. Phenotypic and molecular characterization of the claudin-low intrinsic subtype of breast cancer. Breast cancer research. 2010; 12:R68. doi: 10.1186/bcr2635.

19. Hedenfalk I, Duggan D, Chen Y, Radmacher M, Bittner M, Simon R, Meltzer P, Gusterson B, Esteller M, Kallioniemi OP, Wilfond B, Borg A, Trent J, et al. Gene-expression profiles in hereditary breast cancer. The New England journal of medicine. 2001; 344:539-548. doi: 10.1056/ NEJM200102223440801.
20. Crabb SJ, Cheang MC, Leung S, Immonen T, Nielsen TO, Huntsman DD, Bajdik CD and Chia SK. Basal breast cancer molecular subtype predicts for lower incidence of axillary lymph node metastases in primary breast cancer. Clinical breast cancer. 2008; 8:249-256. doi: 10.3816/CBC.2008.n.028.

21. Larsen MJ, Kruse TA, Tan Q, Laenkholm AV, Bak M, Lykkesfeldt AE, Sorensen KP, Hansen TV, Ejlertsen B, Gerdes AM and Thomassen M. Classifications within molecular subtypes enables identification of BRCA1/ BRCA2 mutation carriers by RNA tumor profiling. PloS one. 2013; 8:e64268. doi: 10.1371/journal.pone.0064268.

22. Tkocz D, Crawford NT, Buckley NE, Berry FB, Kennedy RD, Gorski JJ, Harkin DP and Mullan PB. BRCA1 and GATA3 corepress FOXC1 to inhibit the pathogenesis of basal-like breast cancers. Oncogene. 2012; 31:3667-3678. doi: 10.1038/onc.2011.531.

23. Sizemore GM, Sizemore ST, Pal B, Booth CN, Seachrist DD, Abdul-Karim FW, Kume T and Keri RA. FOXC1 is enriched in the mammary luminal progenitor population, but is not necessary for mouse mammary ductal morphogenesis. Biology of reproduction. 2013; 89:10. doi: 10.1095/biolreprod.113.108001.

24. Liu S, Ginestier C, Charafe-Jauffret E, Foco H, Kleer CG, Merajver SD, Dontu G and Wicha MS. BRCA1 regulates human mammary stem/progenitor cell fate. Proceedings of the National Academy of Sciences of the United States of America. 2008; 105:1680-1685. doi: 10.1073/pnas.0711613105.

25. Aldinger KA, Lehmann OJ, Hudgins L, Chizhikov VV, Bassuk AG, Ades LC, Krantz ID, Dobyns WB and Millen $\mathrm{KJ}$. FOXC1 is required for normal cerebellar development and is a major contributor to chromosome 6p25.3 DandyWalker malformation. Nature genetics. 2009; 41:10371042. doi: 10.1038/ng.422.

26. Omatsu Y, Seike M, Sugiyama T, Kume T and Nagasawa T. Foxc1 is a critical regulator of haematopoietic stem/ progenitor cell niche formation. Nature. 2014; 508:536-540. doi: 10.1038/nature13071.

27. Lambers E, Arnone B, Fatima A, Qin G, Wasserstrom JA and Kume T. Foxc1 Regulates Early Cardiomyogenesis and Functional Properties of Embryonic Stem Cell Derived Cardiomyocytes. Stem cells (Dayton, Ohio). 2016; 34:14871500. doi: 10.1002/stem.2301.

28. Lay K, Kume T and Fuchs E. FOXC1 maintains the hair follicle stem cell niche and governs stem cell quiescence to preserve long-term tissue-regenerating potential. Proceedings of the National Academy of Sciences of the United States of America. 2016; 113:E1506-1515. doi: 10.1073/pnas.1601569113.

29. Wang L, Siegenthaler JA, Dowell RD and Yi R. Foxc1 reinforces quiescence in self-renewing hair follicle stem cells. Science. 2016; 351:613-617. doi: 10.1126/science.aad5440.

30. Stute P, Sielker S, Wood CE, Register TC, Lees CJ, Dewi FN, Williams JK, Wagner JD, Stefenelli U and Cline JM. Life stage differences in mammary gland gene expression profile in non-human primates. Breast cancer 
research and treatment. 2012; 133:617-634. doi: 10.1007/ s10549-011-1811-9.

31. Somerville TD, Wiseman DH, Spencer GJ, Huang X, Lynch JT, Leong HS, Williams EL, Cheesman E and Somervaille TC. Frequent Derepression of the Mesenchymal Transcription Factor Gene FOXC1 in Acute Myeloid Leukemia. Cancer cell. 2015; 28:329-342.

32. Xia L, Huang W, Tian D, Zhu H, Qi X, Chen Z, Zhang Y, $\mathrm{Hu}$ H, Fan D, Nie Y and Wu K. Overexpression of forkhead box $\mathrm{C} 1$ promotes tumor metastasis and indicates poor prognosis in hepatocellular carcinoma. Hepatology. 2013; 57:610-624. doi: 10.1002/hep.26029.

33. Yao T, Wang Q, Zhang W, Bian A and Zhang J. Identification of genes associated with renal cell carcinoma using gene expression profiling analysis. Oncology letters. 2016; 12:73-78. doi: 10.3892/ol.2016.4573.

34. Xu Y, Shao QS, Yao HB, Jin Y, Ma YY and Jia LH. Overexpression of FOXC1 correlates with poor prognosis in gastric cancer patients. Histopathology. 2014; 64:963970. doi: 10.1111/his.12347.

35. Wei LX, Zhou RS, Xu HF, Wang JY and Yuan MH. High expression of FOXC1 is associated with poor clinical outcome in non-small cell lung cancer patients. Tumour biology. 2013; 34:941-946. doi: 10.1007/s13277-012-0629-3.

36. Taube JH, Herschkowitz JI, Komurov K, Zhou AY, Gupta S, Yang J, Hartwell K, Onder TT, Gupta PB, Evans KW, Hollier BG, Ram PT, Lander ES, et al. Core epithelialto-mesenchymal transition interactome gene-expression signature is associated with claudin-low and metaplastic breast cancer subtypes. Proceedings of the National Academy of Sciences of the United States of America. 2010; 107:15449-15454. doi: 10.1073/pnas.1004900107.

37. Powell AA, Talasaz AH, Zhang H, Coram MA, Reddy A, Deng G, Telli ML, Advani RH, Carlson RW, Mollick JA, Sheth S, Kurian AW, Ford JM, et al. Single cell profiling of circulating tumor cells: transcriptional heterogeneity and diversity from breast cancer cell lines. PloS one. 2012; 7:e33788. doi: 10.1371/journal.pone.0033788.

38. Sizemore ST and Keri RA. The forkhead box transcription factor FOXC1 promotes breast cancer invasion by inducing matrix metalloprotease 7 (MMP7) expression. The Journal of biological chemistry. 2012; 287:24631-24640. doi: 10.1074/jbc.M112.375865.

39. Han B, Qu Y, Jin Y, Yu Y, Deng N, Wawrowsky K, Zhang X, Li N, Bose S, Wang Q, Sakkiah S, Abrol R, Jensen TW, et al. FOXC1 Activates Smoothened-Independent Hedgehog Signaling in Basal-like Breast Cancer. Cell reports. 2015; 13:1046-1058. doi: 10.1016/j.celrep.2015.09.063.

40. Jin Y, Han B, Chen J, Wiedemeyer R, Orsulic S, Bose S, Zhang X, Karlan BY, Giuliano AE, Cui Y and Cui X.
FOXC1 is a Critical Mediator of EGFR Function in Human Basal-like Breast Cancer. Annals of surgical oncology. 2014. doi: 10.1245/s10434-014-3980-3.

41. Kubista M, Rosner M, Kubista E, Bernaschek G and Hengstschlager M. Brcal regulates in vitro differentiation of mammary epithelial cells. Oncogene. 2002; 21:47474756. doi: 10.1038/sj.onc.1205580.

42. Furuta S, Jiang X, Gu B, Cheng E, Chen PL and Lee WH. Depletion of BRCA1 impairs differentiation but enhances proliferation of mammary epithelial cells. Proceedings of the National Academy of Sciences of the United States of America. 2005; 102:9176-9181. doi: 10.1073/ pnas.0503793102.

43. Lim E, Vaillant F, Wu D, Forrest NC, Pal B, Hart AH, Asselin-Labat ML, Gyorki DE, Ward T, Partanen A, Feleppa F, Huschtscha LI, Thorne HJ, et al. Aberrant luminal progenitors as the candidate target population for basal tumor development in BRCA1 mutation carriers. Nature medicine. 2009; 15:907-913. doi: 10.1038/nm.2000.

44. Hammond ME, Hayes DF, Dowsett M, Allred DC, Hagerty KL, Badve S, Fitzgibbons PL, Francis G, Goldstein NS, Hayes M, Hicks DG, Lester S, Love R, et al. American Society of Clinical Oncology/College Of American Pathologists guideline recommendations for immunohistochemical testing of estrogen and progesterone receptors in breast cancer. Journal of clinical oncology. 2010; 28:2784-2795. doi: 10.1200/JCO.2009.25.6529.

45. Dowsett M, Nielsen TO, A'Hern R, Bartlett J, Coombes RC, Cuzick J, Ellis M, Henry NL, Hugh JC, Lively T, McShane L, Paik S, Penault-Llorca F, et al. Assessment of Ki67 in breast cancer: recommendations from the International Ki67 in Breast Cancer working group. Journal of the National Cancer Institute. 2011; 103:1656-1664. doi: 10.1093/jnci/djr393.

46. Nielsen TO, Hsu FD, Jensen K, Cheang M, Karaca G, Hu Z, Hernandez-Boussard T, Livasy C, Cowan D, Dressler L, Akslen LA, Ragaz J, Gown AM, et al. Immunohistochemical and clinical characterization of the basal-like subtype of invasive breast carcinoma. Clinical cancer research. 2004; 10:5367-5374. doi: 10.1158/10780432.CCR-04-0220.

47. Neve RM, Chin K, Fridlyand J, Yeh J, Baehner FL, Fevr T, Clark L, Bayani N, Coppe JP, Tong F, Speed T, Spellman PT, DeVries S, et al. A collection of breast cancer cell lines for the study of functionally distinct cancer subtypes. Cancer cell. 2006; 10:515-527. doi: 10.1016/j. ccr.2006.10.008.

48. Ran FA, Hsu PD, Wright J, Agarwala V, Scott DA and Zhang F. Genome engineering using the CRISPR-Cas9 system. Nature protocols. 2013; 8:2281-2308. doi: 10.1038/ nprot.2013.143. 